\title{
Pregnancy outcomes in interferon-beta-exposed patients with multiple sclerosis: results from the European Interferon-beta Pregnancy Registry
}

\author{
Kerstin Hellwig ${ }^{1}$ (D) Yvonne Geissbuehler ${ }^{2} \cdot$ Meritxell Sabidó $^{3}$. Catrinel Popescu ${ }^{4}$. Alessandra Adamo ${ }^{5}$. \\ Joachim Klinger ${ }^{6} \cdot$ Asher Ornoy $^{7} \cdot$ Peter Huppke ${ }^{8}$ on behalf of the European Interferon-beta Pregnancy Study \\ Group
}

Received: 14 October 2019 / Revised: 11 February 2020 / Accepted: 12 February 2020

(c) The Author(s) 2020

\begin{abstract}
Background Family planning is an important consideration for women with multiple sclerosis (MS), who are often diagnosed during their reproductive years. Currently, limited data are available on pregnancy outcomes in patients exposed to interferon-beta (IFN-beta) before or during pregnancy. Here, we present the cumulative pregnancy exposure data and prevalence of pregnancy and infant outcomes in IFN-beta-exposed pregnant women with MS from the European IFN-beta Pregnancy Registry.

Methods Using spontaneous and solicited reports, the registry collected data from 26 countries of the European Economic Area, consisting of information on women with MS identifying themselves to one of the Marketing Authorisation Holders (Bayer, Biogen, Merck KGaA, and Novartis) or healthcare professionals as pregnant and exposed to IFN-beta during pregnancy or within 1 month before conception. The outcomes collected by the registry included ectopic pregnancies, spontaneous abortions, elective terminations, live, and stillbirths with or without congenital anomalies. The prevalence of pregnancy outcomes was put in context with those reported in the general population.

Results Between 2009 and 2017, the registry collected 948 pregnancy reports with a known pregnancy outcome. Overall, $82.0 \%$ (777/948) of pregnancies resulted in live birth without congenital anomaly. When comparing IFN-beta-exposed pregnancies with the general population, the prevalence of spontaneous abortions (10.7\% vs. 10-21\%) and congenital anomalies in live births $(2.1 \%$ vs. $2.1-4.1 \%)$ were found to be within reported ranges.

Conclusions The data gathered from these pregnancy cases suggest no evidence that IFN-beta exposure before conception and/or during pregnancy adversely increases the rate of congenital anomalies or spontaneous abortions.
\end{abstract}

Keywords Multiple sclerosis $\cdot$ Interferon-beta $\cdot$ Disease-modifying drugs $\cdot$ Pregnancy $\cdot$ Congenital anomalies Spontaneous abortions

Asher Ornoy and Peter Huppke are senior co-authors.

Supplementary Information The online version of this article (https://doi.org/10.1007/s00415-020-09762-y) contains supplementary material, which is available to authorized users.

Kerstin Hellwig

k.hellwig@klinikum-bochum.de

Extended author information available on the last page of the article

\section{Introduction}

Family planning is an important consideration for female patients with multiple sclerosis (MS) who are receiving treatment with disease modifying drugs (DMDs) that may be contraindicated in pregnancy. The introduction of DMDs for the treatment of MS over 20 years ago has improved clinical outcomes for many patients, yet studies at this time were limited and did not address concerns regarding the potential adverse effects of DMDs on pregnancy and infant outcomes [1]. Patients are, therefore, advised to discuss treatment options with their healthcare professional (HCP) prior to family planning, and in many instances, it may be 
recommended, or even required, for a woman to discontinue her treatment with DMDs during pregnancy planning or once pregnancy is confirmed.

There is currently no consensus in the literature regarding MS treatment up to and during pregnancy. Clinical treatment guidelines recommend that injectables such as interferonbeta (IFN-beta) are continued until pregnancy occurs; however, the current evidence to support this is considered weak based on the quality of evidence and risk-benefit balance [2-4]. There are some data, suggesting that exposure to IFNbeta during pregnancy may lead to an increased risk of lower mean birth weight, shorter mean birth length, and preterm birth (generally considered as a birth before 37 weeks of gestation) [5-8]. However, in recent years, several systematic reviews $[5,9,10]$ and observational studies $[6-8,11-15]$ have shown no increase in adverse pregnancy outcomes in patients exposed to IFN-beta before or during pregnancy.

Data on the risks of IFN-beta use during pregnancy were limited at the time which the DMDs were launched by their respective pharmaceutical companies (Betaseron ${ }^{\circledR}$, Bayer AG; Avonex ${ }^{\circledR}$ and Plegridy ${ }^{\circledR}$, Biogen; Rebif ${ }^{\circledR}$, Merck KGaA; and Extavia ${ }^{\circledR}$, Novartis Pharma AG). The prospective European IFN-beta Pregnancy Registry was initiated in 2009 at the request of the Committee for Medicinal Products for Human Use (CHMP), to address the lack of evidence on the safety of IFN-beta treatment before conception and during pregnancy. The registry was comprised of spontaneous and solicited reports from patient support programmes and pharmacovigilance databases conducted by the Market Authorisation Holders (MAHs), Bayer AG, Biogen, Merck KGaA, and Novartis Pharma AG.

Here, we present the final cumulative pregnancy exposure data and prevalence of pregnancy and infant outcomes in IFN-beta-exposed pregnant women from the European IFNbeta Pregnancy Registry.

\section{Patients and methods}

\section{Study design}

The European IFN-beta Pregnancy Registry was a prospective observational collection of data from women exposed to IFN-beta before and/or during pregnancy and their pregnancy outcomes. Data collected by each MAH from 26 countries within the European Economic Area (Supplementary Table 1) were transferred to a central repository for pooled analysis. Data on pregnancy exposure were acquired prior to the knowledge of pregnancy outcome, or prior to the detection of a congenital anomaly at prenatal examination. All patients included in the analysis were receiving either IFN-beta-1a (Avonex ${ }^{\circledR}$, Plegridy ${ }^{\circledR}$ or Rebif ${ }^{\circledR}$ ) or IFN-beta-1b
(Betaferon ${ }^{\circledR}$ or Extavia ${ }^{\circledR}$ ). All patients gave their informed consent prior to their inclusion in the analysis.

Data were collected from individual case-safety reports (ICSR) spontaneously reported to the pharmacovigilance databases and solicited reports from patient support programmes conducted by the four MAHs and reported to MAH pharmacovigilance databases. Prospective data from spontaneously reported cases on HCP-confirmed pregnancies with a confirmed diagnosis of MS were included in the registry between 01 April 2009 and 16 June 2017. In addition, after 2015, cases without a confirmed MS diagnosis, pregnancies not confirmed by an HCP, and solicited reports from prospectively identified patient support programmes were included in the registry.

\section{Study participants}

Women who identified themselves to the MAHs or an HCP as being pregnant and who had been exposed to IFN-beta were eligible for this analysis. Data from women with a diagnosis of MS, who were pregnant and did not know the potential pregnancy outcome, and who had been prescribed one of the five approved IFN-beta therapies within 1 month before conception or at any time during pregnancy were included in the registry. Women were excluded from the registry if pregnancy outcome was known at the time of initial contact. Reports were followed prospectively for outcomes.

\section{Definition of exposure and outcomes}

The start of pregnancy was defined as the first day of last menstrual period (LMP). Pregnant women prescribed IFN-beta were considered exposed if they received at least one prescription of IFN-beta at any dose within 1 month before conception or at any time during pregnancy. Timing of treatment exposure was classified by the latest trimester with exposure to IFN-beta; before conception (within 1 month before conception), first ( $0-13$ weeks), second (14-26 weeks), third trimester (27-40 weeks), or timing unknown.

The possible pregnancy outcomes were ectopic pregnancy, spontaneous abortions, elective terminations, stillbirths, and live births with and without congenital anomalies.

Using the European Medicines Agency (EMA) guidelines [16], spontaneous abortions were defined as a pregnancy which spontaneously ended before 22 weeks of gestation, and included abortion, miscarriage, missed abortion, incomplete abortion, and early foetal death. Stillbirths were defined as a foetal death occurring after 22 weeks of pregnancy, further defined as foetal death in the uterus or during labour. A congenital anomaly was defined as a morphological 
functional and/or biomedical developmental disturbance in the embryo or foetus whether detected at birth or not.

\section{Statistical analysis}

For the sample size calculation, it was estimated that at least 827 pregnancy cases exposed to IFN-beta with known pregnancy outcomes were required to detect a doubling in the prevalence of congenital anomalies compared with the general population (average reported prevalence rate $=3 \%$ ) [17], with $80 \%$ power and 5\% significance level.

Cases included in the registry were categorised into two groups according to their origin: (1) HCP-confirmed pregnancy reports received from an $\mathrm{HCP}$, and (2) non-HCPconfirmed pregnancy reports received from a patient, either spontaneously or when solicited (i.e., provided by a patient support programme).

The prevalence of each study outcome, with the associated $95 \%$ confidence interval (CI), was estimated using the number of events divided by the total number of pregnancy cases with a known outcome. Elective terminations and stillbirths were classified according to the presence of foetal defects, and live births according to the presence of congenital anomalies following the EMA guidelines [16]. The prevalence of congenital anomalies was estimated among live births, still births, and elective terminations with known outcomes.

Pregnancy cases without outcome present were categorised by those with: (1) pending outcome, defined as no occurrence of birth at time of data lock, and (2) unknown outcome, defined as those who were lost to follow-up. Follow-up contact was made with the patients' HCP to obtain outcome data 1 month after the expected delivery date. The time between expected delivery date and the first follow-up attempt was 1 month, similar to the interval between subsequent follow-up attempts. Cases were defined as 'lost to follow-up' when all follow-up attempts were made without success. For the 'pending' cases, no further attempt to contact the individual was made after three attempts, as described in the protocol, at which time they became lost to follow-up (hence 'outcome unknown').

The prevalence of pregnancy outcomes was calculated for the total number of cases, and as a sensitivity analysis for cases that met the original inclusion criteria, i.e., spontaneously reported cases of HCP-confirmed pregnancies where the mother also had a confirmed diagnosis of MS. These results were put in context with the general population using the published data [18-23].

Adverse events were reported in the infant/foetus cases (i.e., exposed to IFN-beta via the mother 1 month before and/or during pregnancy). Adverse events were coded using the Medical Dictionary of Regulatory Activities (MedDRA v21.1) preferred term in events occurring in all cases.

\section{Results}

\section{Study participants and data}

Between 01 April 2009 and 16 June 2017, a total of 2447 pregnancy reports were collected by the pharmacovigilance databases of the four MAHs, consisting of 1486 solicited reports and 961 spontaneous reports. These reports were further comprised of 312 spontaneous HCP-confirmed pregnancy cases with a confirmed diagnosis of MS, along with 2135 cases from patient support programmes with unconfirmed diagnosis of MS or an unconfirmed pregnancy.

From the 2447 pregnancy reports collected, 948 (38.7\%) cases had a known outcome, with the remaining cases either pending outcomes or patients that were lost to follow-up. Of the pregnancies with known outcome, 412 (43.5\%) cases were spontaneously reported: with $210(22.2 \%)$ cases of HCP-confirmed pregnancy, and 158 (16.7\%) cases of HCP-confirmed pregnancy and a confirmed diagnosis of MS. Of the total number of pregnancies with known outcome, 795 (83.9\%) cases had a confirmed diagnosis of MS (Fig. 1).

\section{Overall prevalence of pregnancy and infant outcomes}

A total of $82.0 \%$ (777/948; 95\% CI 79.36-84.36) of the pregnancy reports included in the European IFN-beta Pregnancy Registry had an outcome of live birth without congenital anomalies (Table 1). The remaining $18.0 \%$ of pregnancy reports are broken down as follows: ectopic pregnancies represented 0.4\% (4/948; 95\% CI 0.12-1.08); spontaneous abortions represented $10.7 \%$ (101/948; 95\% CI 8.76-12.79); the prevalence of elective terminations was $0.6 \%(6 / 948 ; 95 \%$ CI $0.23-1.37)$ for those with foetal defects and $4.2 \%$ (40/948; 95\% CI 3.03-5.70) without foetal defects, or unknown defects. Stillbirths with and without foetal defects had a prevalence of $0.1 \%$ (1/948; 95\% CI 0.00-0.59) and 0.2\% (2/948; 95\% CI 0.03-0.76), respectively. Finally, the prevalence of live birth with any congenital anomalies was $1.8 \%(17 / 948 ; 95 \%$ CI 1.05-2.86).

The prevalence of spontaneous abortions and congenital anomalies in live births remained within the ranges reported in the general population ( $10.7 \%$ vs. $10-21 \%$ [18], and $2.1 \%$ vs. $2.1-4.1 \%$, respectively) $[19,21]$. This was also the case for the prevalence of congenital anomalies in live births, still births, and elective terminations (2.8\% vs. 2.6-6.9\%) [22] (Fig. 2).

\section{Prevalence of pregnancy and infant outcomes by timing of exposure}

The latest timing of exposure was known in 73.2\% (694/948) cases (Table 1). Among those cases, the majority of 
Fig. 1 Total number of pregnancy cases by presence of outcome for all reported individual case safety reports

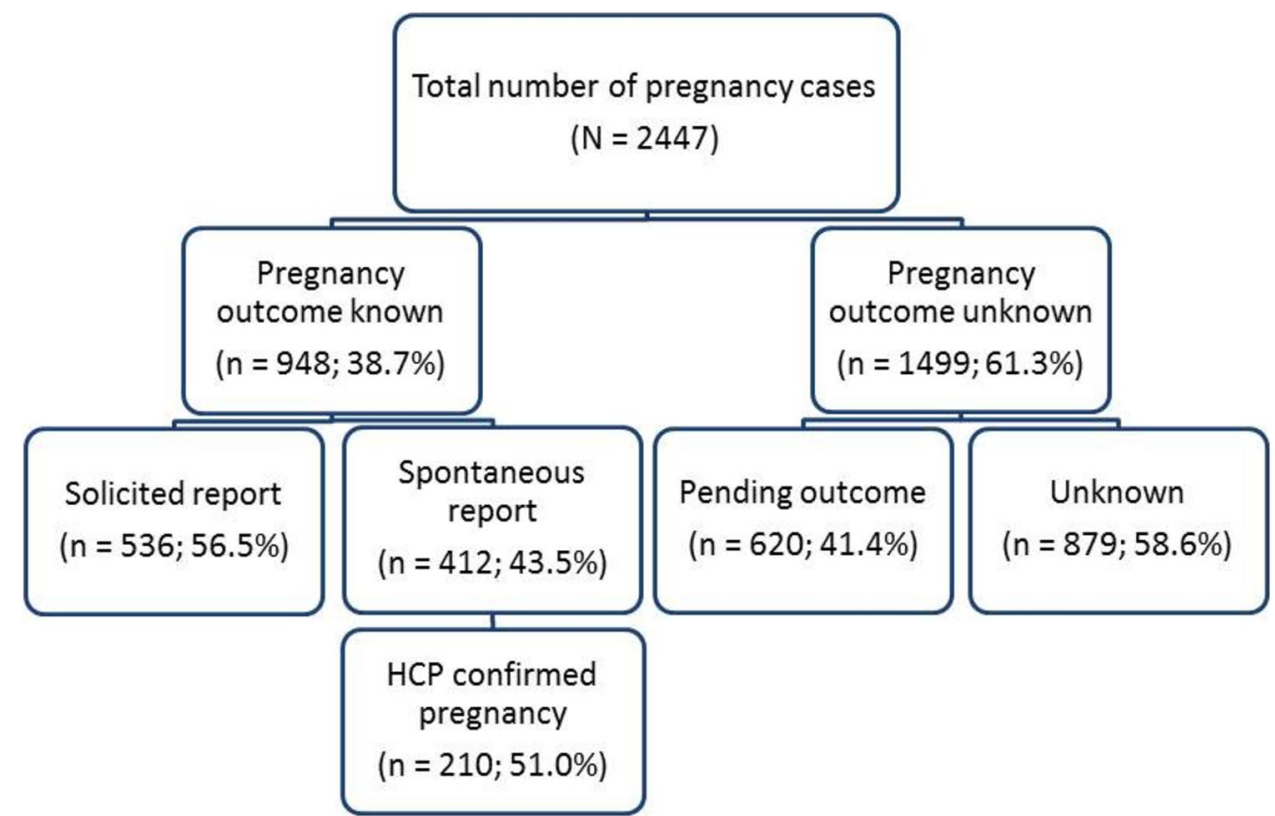

Table 1 Cumulative number of individual case-safety reports and prevalence by pregnancy outcome and latest trimester of exposure to IFN-beta cases

\begin{tabular}{|c|c|c|c|c|c|c|c|}
\hline \multirow{2}{*}{ Pregnancy or infant outcome, $n(\%)$} & \multicolumn{5}{|c|}{ Timing of IFN-beta exposure in pregnancy } & \multirow{2}{*}{$\begin{array}{l}\text { Total } \\
(n=948)\end{array}$} & \multirow{2}{*}{$\begin{array}{l}\text { Exact } \\
95 \% \mathrm{CI}\end{array}$} \\
\hline & $\begin{array}{l}\text { Before } \\
\text { conception } \\
(n=90)\end{array}$ & $\begin{array}{l}\text { First } \\
\text { trimester } \\
(n=573)\end{array}$ & $\begin{array}{l}\text { Second } \\
\text { trimester } \\
(n=23)\end{array}$ & $\begin{array}{l}\text { Third } \\
\text { trimester } \\
(n=8)\end{array}$ & $\begin{array}{l}\text { Timing unknown } \\
(n=254)\end{array}$ & & \\
\hline Ectopic pregnancies & $0(0.0)$ & $1(0.2)$ & $0(0.0)$ & $0(0.0)$ & $3(1.2)$ & $4(0.4)$ & $0.12-1.08$ \\
\hline Spontaneous abortion* & $2(2.2)$ & $53(9.2)$ & $0(0.0)$ & $1(12.5)$ & $45(17.7)$ & $101(10.7)$ & $8.76-12.79$ \\
\hline Elective termination (foetal defects) & $2(2.2)$ & $4(0.7)$ & $0(0.0)$ & $0(0.0)$ & $0(0.0)$ & $6(0.6)$ & $0.23-1.37$ \\
\hline $\begin{array}{l}\text { Elective termination (no foetal defects/ } \\
\text { unknown) }\end{array}$ & $2(2.2)$ & $23(4.0)$ & $0(0.0)$ & $0(0.0)$ & $15(5.9)$ & $40(4.2)$ & $3.03-5.70$ \\
\hline Stillbirth with foetal defects & $0(0.0)$ & $1(0.2)$ & $0(0.0)$ & $0(0.0)$ & $0(0.0)$ & $1(0.1)$ & $0.00-0.59$ \\
\hline Stillbirth without foetal defects & $0(0.0)$ & $1(0.2)$ & $1(4.3)$ & $0(0.0)$ & $0(0.0)$ & $2(0.2)$ & $0.03-0.76$ \\
\hline Live birth with congenital anomaly & $2(2.2)$ & $8(1.4)$ & $1(4.3)$ & $0(0.0)$ & $6(2.4)$ & $17(1.8)$ & $1.05-2.86$ \\
\hline Live birth without congenital anomaly & $82(91.1)$ & $482(84.1)$ & $21(91.3)$ & $7(87.5)$ & $185(72.8)$ & $777(82.0)$ & $79.36-84.36$ \\
\hline
\end{tabular}

CI confidence interval, IFN-beta interferon-beta

*Spontaneous abortion defined as when the pregnancy spontaneously ends before 22 completed weeks of gestation $(<24$ weeks from last mentsrual period). This comprises spontaneous abortion, miscarriage, missed abortion, incomplete abortion, and early foetal death

pregnancies were last exposed to IFN-beta before conception $(13.0 \%$; 90/694) or during the first trimester $(82.6 \%$; $573 / 694$ ), with only a few pregnancies last exposed to IFNbeta during the second and third trimesters $(3.3 \% ; 23 / 694$ and $1.2 \% ; 8 / 694$, respectively). The mean duration of exposure during pregnancy was 4.31 weeks with a standard deviation of 5.44 (Supplementary Table 1).

The prevalence of live births with congenital anomalies among the 573 cases with known outcomes and with exposure to IFN-beta during the first trimester was 1.4\% (8/573). Exposure during the second or third trimesters occurred in 31 cases with a known outcome; of these cases, there were three reports of abnormal pregnancy outcomes: one stillbirth without foetal defects, one live birth with congenital anomaly (both cases were exposed during the second trimester), and one spontaneous abortion (reported during the third trimester, despite not being in accordance with the EMA definition of spontaneous abortion).

\section{Sensitivity analysis of pregnancy and infant outcomes by source of case}

A sensitivity analysis was conducted to evaluate the differences between the spontaneous and solicited case reports. 


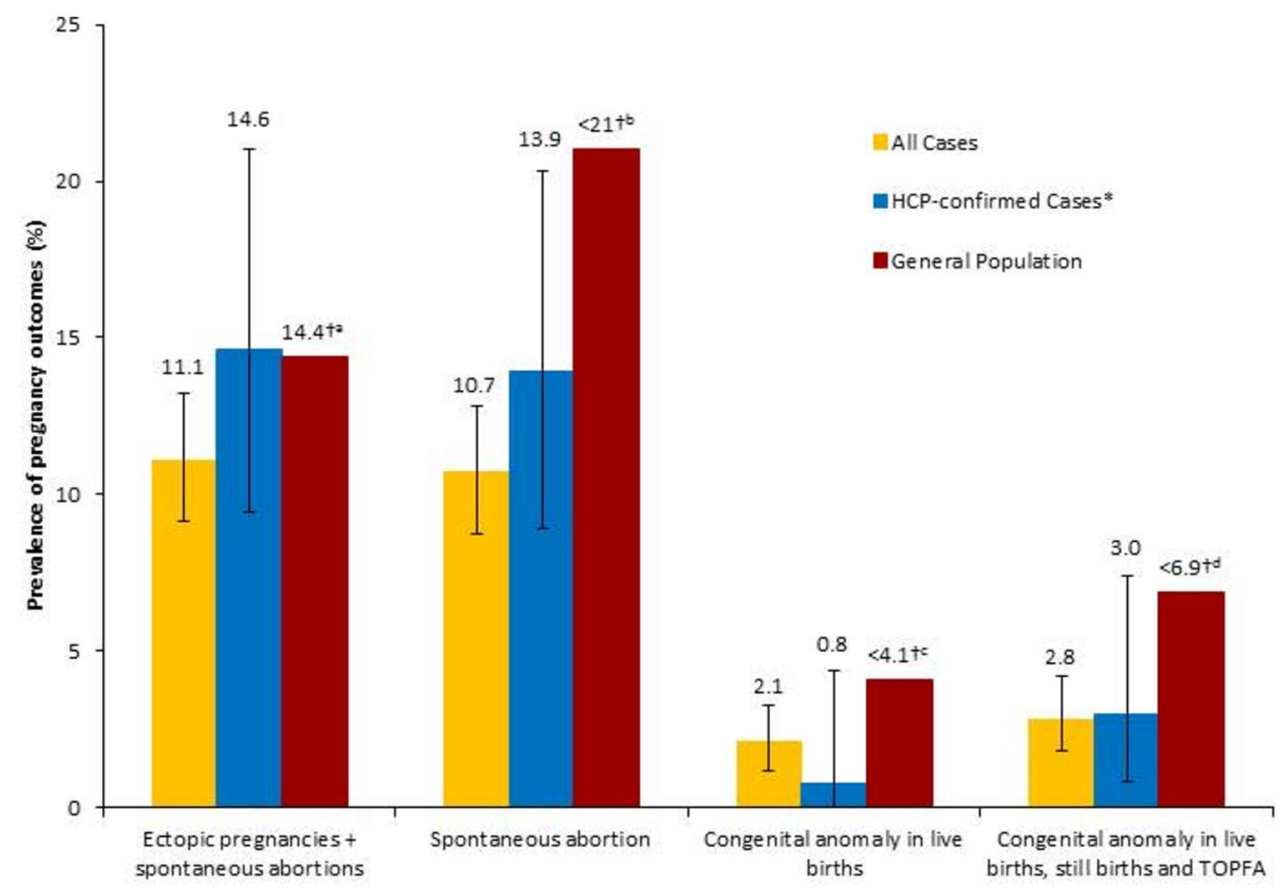

Fig. 2 Prevalence of pregnancy and infant outcomes in women exposed to IFN-beta: all cases, in HCP-confirmed cases of pregnancy with confirmed diagnosis of MS, and the general population. Prevalence data are shown with 95\% confidence interval for each population from the European IFN-beta Pregnancy Registry. *HCPconfirmed spontaneously reported pregnancy cases with confirmed

This analysis found that in the spontaneously reported population, the prevalence of live births with congenital anomaly was $0.7 \%(3 / 412$; 95\% CI $0.15-2.11)$, still birth with foetal defects was $0.5 \%(2 / 412 ; 95 \%$ CI $0.06-1.74)$, and elective terminations with foetal defects was $1.0 \%$ (4/412; 95\% CI 0.27-2.47) (Supplementary Table 2a). In the solicited population, the prevalence of live births with congenital anomaly was $2.6 \%$ (14/536; $95 \%$ CI 1.44-4.34); still birth with foetal defects was $0.2 \%(1 / 412 ; 95 \%$ CI $0.00-0.69)$; and elective terminations with foetal defects were $0.4 \%(2 / 412$; $95 \%$ CI $0.05-1.34)$ (Supplementary Table $2 b$ ), thus, indicating there are a few differences in the distribution of outcomes between the spontaneous versus solicited populations.

\section{Adverse events in infants exposed to IFN-beta before and/or during pregnancy}

A total of 216 adverse events, including low birth weight and premature births, were reported in 98 infant/foetus cases exposed to IFN-beta via the mother during pregnancy. A broad range of adverse events were collected in the registry; however, no patterns of congenital anomalies were observed. diagnosis of MS. ${ }^{\dagger}$ Values denote the maximum estimate from the general population as obtained from available literature. ${ }^{a}$ Wang et al. [23]; 'buss et al. [18]; ' Congenital Malformations Registry [21]; ${ }^{\mathrm{d}}$ Queisser-Luft et al. [22]. $H C P$ healthcare professional, $M S$ multiple sclerosis, TOPFA termination of pregnancy for foetal anomaly

The congenital anomalies in cases of live birth (term births, preterm births, and not specified), still birth, and elective termination are described in Table 2.

\section{Discussion}

Between 2009 and 2017, a total of 948 pregnancy cases with known outcomes were identified in which the prevalence of spontaneous abortions, congenital anomalies in live births and live births, still births, and elective terminations remained within the ranges reported in the general population $(10.7 \%$ vs. up to $10-21 \%$ [18], $2.1 \%$ vs. $2.1-4.1 \%$ [ 19 , $21]$ and $2.8 \%$ vs. $2.6-6.9 \%$ [22], respectively) (Fig. 2). This similarity was also observed when considering only the HCP-confirmed, spontaneously reported cases with a confirmed diagnosis of MS. A number of systematic literature reviews and observational studies have been published on the effect of IFN-beta exposure during pregnancy and the related pregnancy outcomes. Overall, the rates of congenital anomalies and spontaneous abortions reported in these studies are comparable with the rates reported in the general population [5, 9]. The estimated prevalence of pregnancy outcomes among IFN-beta-exposed patients, collected by the European IFN-beta Pregnancy Registry, in all cases 
Table 2 Congenital anomalies in cases of live birth (term births, preterm births, and not specified), still birth and elective termination

\begin{tabular}{ll}
\hline Case number & Pregnancy outcome \\
\hline 1 & Term live birth \\
2 & Term live birth
\end{tabular}

Congenital anomalies/foetal disorder

Persistent foetal circulation

Congenital ureterovesical junction anomaly

Congenital urinary tract obstruction

Congenital vesicoureteric reflux

Ectopic kidney

Renal aplasia

Developmental hip dysplasia

Developmental hip dysplasia

Cryptorchism

Ventricular septal defect

Congenital joint malformation

Ventricular septal defect

Foetal distress syndrome

Hypoxic-ischaemic encephalopathy

Foetal growth restriction

Cerebral ischaemia

\begin{tabular}{lll}
10 & Not specified live birth & Developmental hip dysplasia \\
11 & Not specified live birth & Cleft palate \\
12 & Not specified live birth & Cerebral cyst \\
& & Heart disease congenital \\
& & Thymus hypoplasia \\
13 & Not specified live birth & Ventricular septal defect \\
14 & Not specified live birth & Heart disease congenital \\
15 & Preterm live birth & Vocal cord paresis \\
16 & Preterm live birth & Trisomy 21 \\
& & Duodenal atresia \\
17 & Preterm live birth & Asphyxia \\
18 & & Renal failure neonatal \\
19 & Elective termination & Trisomy 21 \\
20 & Elective termination & Anencephaly \\
21 & Elective termination & Eagle Barrett syndrome \\
22 & Elective termination & Congenital renal disorder \\
23 & Elective termination & Foetal disorder \\
24 & Elective termination & Foetal growth restriction \\
\hline
\end{tabular}

including those that were spontaneously reported cases of HCP-confirmed pregnancies with a confirmed diagnosis of MS, remained within the ranges reported for the general population. Based on these results, there is no evidence of a signal, suggesting that exposure to IFN-beta before conception and/or during the first trimester of pregnancy adversely increases the rate of congenital anomalies or spontaneous abortions. Sensitivity analyses showed that the pregnancy outcomes of the cases included after 2015 were comparable between spontaneous and solicited cases (Fig. 2).

The results presented in Table 1 show that in the majority of pregnancy cases, IFN-beta treatment was stopped during the first trimester, a time at which most women become aware that they are pregnant, and that there is no evidence of a signal suggesting exposure to IFN-beta during this period adversely affects pregnancy or infant outcomes. Similar results have been shown in other observational studies, where exposure in the early stages of pregnancy has not been shown to worsen pregnancy outcomes [7, 8, 12, 14]. The European IFN-beta Pregnancy Registry collected a limited number of pregnancies exposed to IFN-beta during the second and third trimesters $(3.3 \% ; 31 / 948)$, so it is not possible to determine the impact of IFN-beta exposure during the latter stages of pregnancy; however, exposure occurred at a critical time in organ development [24]. In previous studies, the timing of exposure to IFN-beta was also relatively narrow, with a very low number of pregnancies being exposed to IFNbeta beyond the first trimester. Mean duration of foetal exposure time to IFN-beta ranged from 4.0 to 9.1 weeks 
$[5-8,12,14]$. It should be noted that Table 1 presents one spontaneous abortion that occurred during the third trimester. This may be due to an error in which a pregnancy case was incorrectly reported to the pharmacovigilance database, and was not possible to be clarified during follow-up. This particular case is not in accordance with the EMA definition of spontaneous abortion and should, therefore, be disregarded.

The European IFN-beta Pregnancy Registry reported a total of 216 adverse events in 98 infant/foetus cases, yet no patterns of congenital anomalies were observed. These findings align with previous studies which found that in cases in which congenital anomalies were present, they did not centre on a specific system organ class $[6,11,13,14]$. The cases of adverse events were reported retrospectively to the pharmacovigilance databases, and as such, 11 cases could not be matched to the mother's case report. It should also be noted that some adverse events in infant/foetus cases may not have been reported to the pharmacovigilance databases due to the case being lost to follow-up.

The number of pregnancy reports from patients who met the initial inclusion criteria did not reach the estimated number of cases required to detect a doubling in outcome prevalence. Therefore, after June 2015, patients with an unconfirmed diagnosis of MS, solicited reports from patient support programmes and pregnancy cases not confirmed by an HCP were permitted to be included in the analysis. Through the inclusion of these cases, the required number of pregnancy reports, calculated to be 827 , was exceeded by 121 pregnancy cases. Sensitivity analyses indicated that the inclusion of the additional non-HCP-confirmed and solicited cases were comparable to the pregnancy outcomes of the cases meeting the original inclusion criteria, and were, therefore, deemed adequate as a measure to reach the required sample size for the analysis. A limitation of this analysis is that $16.1 \%$ of patients with known pregnancy outcome did not have a confirmed diagnosis of MS; however, in Europe, treatment with IFN-beta automatically means that the diagnosis of MS is confirmed by an HCP.

At the end of the study period, approximately $61.3 \%$ of the total numbers of reported cases were either pending outcomes $(25.3 \%)$ or the patients were lost to followup (35.9\%); as such, there may be selection bias for pregnancies with documented outcomes versus those that were not documented. This selection bias may be either towards the presence of adverse pregnancy outcomes or towards a particular subgroup of women who have higher healthcare seeking behaviour. It is also thought that the seriousness of an adverse event contributes to whether or not it is reported, with serious events more likely to be reported than nonserious events [25]. However, it may also be possible that the mothers participating in the pregnancy registry may be healthier, and therefore, the rate of adverse events would be expected to be lower.

The European IFN-beta Pregnancy Registry did not separate the pregnancy outcomes by treatment type (i.e., IFN-beta-1a and beta-1b) to determine the adverse pregnancy outcomes associated with each treatment. However, if the results were separated for analysis, then the statistical power within each treatment group would be limited and meaningful conclusions could not be drawn from the data. Due to the design of the study, it was not possible to determine the dose or duration of IFN-beta exposure prior to conception and pregnancy. Therefore, it cannot be determined if pregnancies with congenital anomalies were associated with higher doses of IFN-beta, longer term DMD use, a combination of these factors, or whether adverse pregnancy outcomes occur regardless of the dosage and length of exposure. It should also be noted that the European IFN-Beta Pregnancy Registry did not adjust for potential confounders including family history, gestational age, parity, previous obstetrical history, smoking and alcohol consumption, comorbidities, or exposure to co-medications, which may have influenced the prevalence results. Nor did the study collect any substantial data on birth weight, birth length, or gestational age at birth to allow for a comprehensive analysis. Furthermore, 375 (54\%) of the 694 cases reported in this study were obtained from patients in Germany; therefore, interpretations should take into consideration the differences in clinical practices between Germany and the rest of the countries participating in this study. Nevertheless, the available data do not suggest any concern regarding the ability to extrapolate the results to the intended target population.

The European IFN-beta Pregnancy Registry was initiated at the request of the CHMP, and was justified by the need to provide HCPs and women of childbearing age with MS additional information on IFN-beta exposure during pregnancy, so that informed treatment decisions can be made. Overall, the results from the European IFN-beta Pregnancy Registry represent the largest prospective cohort providing safety data of women with MS of childbearing age exposed to IFNbeta. Results from the registry showed no evidence that IFNbeta exposure before conception and/or during pregnancy increased the rate of congenital anomalies or spontaneous abortions, thus indicating that treatment with IFN-beta may be continued until pregnancy is confirmed.

Acknowledgements Open Access funding provided by Projekt DEAL. The authors would like to thank the reporters of pregnancy cases that includes, but are not restricted to, patients and healthcare professionals. Medical writing support was provided by Claire Mwape of inScience Communications, Springer Healthcare Ltd, UK, and funded by Bayer AG, Biogen, Merck KGaA and Novartis Pharma AG.

European Interferon-beta Pregnancy Study Group: Metin Akbaba (Bayer AG), Gustavo Borghesi (Bayer AG), Joerg-Peter Bugge (Bayer AG), Elke Detering (Bayer AG), Evra Köfüncü (Bayer AG), Claudia Luenzmann (Bayer AG), Bettina Mueller (Bayer AG), Axel Olivar 
(Bayer AG), Kiliana Suzart-Woischnik (Bayer AG), Eva-Maria Wicklein (Bayer AG), Vanessa Beynon (Biogen), Kate Brown (Biogen), Nicholas Everage (Biogen), Maria Naylor (Biogen), Avni Pandhi (Biogen), Anh Ly (EMD Serono Inc., a business of Merck KGaA, Darmstadt, Germany), Silke Scheller (Merck Healthcare KGaA), Milorad Todorovic (Merck Healthcare KGaA), Dominic Jack (Merck KGaA, Darmstadt, Germany), Yvonne Samsinger (Novartis Pharma AG), Richard Weitzman (Novartis Pharma AG).

Funding This work was supported by Bayer AG, Biogen, Merck KGaA, and Novartis Pharma AG.

\section{Compliance with ethical standards}

Conflicts of interest $\mathrm{KH}$ has received honoraria and research support from Bayer, Biogen, Teva, Novartis, Sanofi Genzyme, and Merck $\mathrm{KGaA}$. YG is an employee of Novartis Pharma AG. MS is an employee of Merck Healthcare KGaA, Darmstadt, Germany. CP is an employee of Biogen. AA is an employee of Bayer AG. JK is an employee of SynteractHCR GmbH. PH has received honoraria and research support from Bayer, Biogen, Novartis, and Merck KGaA, and is a member of the European Interferon-beta Pregnancy Study Group. AO has nothing to disclose.

Ethical standards This article is based on a prospective observational collection of data from women exposed to IFN-beta before and/or during pregnancy and their pregnancy outcomes, and does not contain any studies with human participants performed by any of the authors.

Open Access This article is licensed under a Creative Commons Attribution 4.0 International License, which permits use, sharing, adaptation, distribution and reproduction in any medium or format, as long as you give appropriate credit to the original author(s) and the source, provide a link to the Creative Commons licence, and indicate if changes were made. The images or other third party material in this article are included in the article's Creative Commons licence, unless indicated otherwise in a credit line to the material. If material is not included in the article's Creative Commons licence and your intended use is not permitted by statutory regulation or exceeds the permitted use, you will need to obtain permission directly from the copyright holder. To view a copy of this licence, visit http://creativecommons.org/licenses/by/4.0/.

\section{References}

1. Vaughn C, Bushra A, Kolb C, Weinstock-Guttman B (2018) An update on the use of disease-modifying therapy in pregnant patients with multiple sclerosis. CNS Drugs 32(2):161-178

2. Montalban X, Gold R, Thompson AJ, Otero-Romero S, Amato MP, Chandraratna D et al (2018) ECTRIMS/EAN guideline on the pharmacological treatment of people with multiple sclerosis. Eur J Neurol 25(2):215-237

3. Montalban X, Gold R, Thompson AJ, Otero-Romero S, Amato MP, Chandraratna D et al (2018) ECTRIMS/EAN guideline on the pharmacological treatment of people with multiple sclerosis. Mult Scler 24(2):96-120

4. Dobson R, Dassan P, Roberts M, Giovannoni G, Nelson-Piercy C, Brex PA (2019) UK consensus on pregnancy in multiple sclerosis: 'Association of British Neurologists' guidelines. Pract Neurol. https://doi.org/10.1136/practneurol-2018-002060

5. Lu E, Wang BW, Guimond C, Synnes A, Sadovnick D, Tremlett $\mathrm{H}$ (2012) Disease-modifying drugs for multiple sclerosis in pregnancy: a systematic review. Neurology 79(11):1130-1135
6. Thiel S, Langer-Gould A, Rockhoff M, Haghikia A, QueisserWahrendorf A, Gold R et al (2016) Interferon-beta exposure during first trimester is safe in women with multiple sclerosis-a prospective cohort study from the German Multiple Sclerosis and Pregnancy Registry. Mult Scler 22(6):801-809

7. Patti F, Cavallaro T, Lo Fermo S, Nicoletti A, Cimino V, Vecchio $\mathrm{R}$ et al (2008) Is in utero early-exposure to interferon beta a risk factor for pregnancy outcomes in multiple sclerosis? J Neurol 255(8):1250-1253

8. Amato MP, Portaccio E, Ghezzi A, Hakiki B, Zipoli V, Martinelli $V$ et al (2010) Pregnancy and fetal outcomes after interferon- $\beta$ exposure in multiple sclerosis. Neurology 75(20):1794-1802

9. Alroughani R, Altintas A, Al Jumah M, Sahraian M, Alsharoqi I, AlTahan A et al (2016) Pregnancy and the use of disease-modifying therapies in patients with multiple sclerosis: benefits versus risks. Mult Scler Int 2016:1034912

10. Thone J, Thiel S, Gold R, Hellwig K (2017) Treatment of multiple sclerosis during pregnancy-safety considerations. Expert Opin Drug Saf 16(5):523-534

11. Coyle PK, Sinclair SM, Scheuerle AE, Thorp JM Jr, Albano JD, Rametta MJ (2014) Final results from the Betaseron (interferon beta-1b) Pregnancy Registry: a prospective observational study of birth defects and pregnancy-related adverse events. BMJ Open 4(5):e004536

12. Hellwig K, Haghikia A, Rockhoff M, Gold R (2012) Multiple sclerosis and pregnancy: experience from a nationwide database in Germany. Ther Adv Neurol Disord 5(5):247-253

13. Romero RS, Lunzmann C, Bugge JP (2015) Pregnancy outcomes in patients exposed to interferon beta-1b. J Neurol Neurosurg Psychiatry 86(5):587-589

14. Sandberg-Wollheim M, Alteri E, Moraga MS, Kornmann G (2011) Pregnancy outcomes in multiple sclerosis following subcutaneous interferon beta-1a therapy. Mult Scler 17(4):423-430

15. Weber-Schoendorfer C, Schaefer C (2009) Multiple sclerosis, immunomodulators, and pregnancy outcome: a prospective observational study. Mult Scler 15(9):1037-1042

16. EMEA/CHMP/313666/2005 (2005) Committee for medicinal products for human use (CHMP): guideline on the exposure to medicinal products during pregnancy: need for post-authorisation data. https://www.ema.europa.eu/documents/regulatory-proce dural-guideline/guideline-exposure-medicinal-products-durin g-pregnancy-need-post-authorisation-data_en.pdf. Accessed 16 Jan 2019.

17. World Health Organisation (2016) Congenital anomalies fact sheet. https://www.who.int/news-room/fact-sheets/detail/conge nital-anomalies. Accessed 09 May 2019.

18. Buss L, Tolstrup J, Munk C, Bergholt T, Ottesen B, Gronbaek M et al (2006) Spontaneous abortion: a prospective cohort study of younger women from the general population in Denmark. Validation, occurrence and risk determinants. Acta Obstet Gynecol Scand 85(4):467-475

19. Irisa Z, Vi IA, Gissler M (2014) Monitoring of congenital anomalies in Latvia. Cent Eur J Public Health 22(3):147-152

20. EUROCAT (2019) European Surveillance of Congenital Anomalies, prevalence data tables. https://www.eurocat-network.eu/ ACCESSPREVALENCEDATA/PrevalenceTables. Accessed 16 Jan 2019.

21. Congenital Malformations Registry (2005) Summary report: statistical summary of children born in 1998-2001 and diagnosed through 2003. https://www.health.ny.gov/diseases/congenital _malformations/docs/98report.pdf. Accessed 16 Jan 2019

22. Queisser-Luft A, Stolz G, Wiesel A, Schlaefer K, Spranger J (2002) Malformations in newborn: results based on 30,940 infants and fetuses from the Mainz congenital birth defect monitoring system (1990-1998). Arch Gynecol Obstet 266(3):163-167 
23. Wang JX, Norman RJ, Wilcox AJ (2004) Incidence of spontaneous abortion among pregnancies produced by assisted reproductive technology. Hum Reprod 19(2):272-277

24. Moore KL, Persaud TVN, Torchia MG (2012) Birth defects: the developing human: clinically oriented embryology. Saunders, Philadelphia, pp 471-500
25. Moulis G, Sommet A, Durrieu G, Bagheri H, Lapeyre-Mestre M, Montastruc JL (2012) Trends of reporting of 'serious' vs. 'nonserious' adverse drug reactions over time: a study in the French PharmacoVigilance Database. Br J Clin Pharmacol 74(1):201-204

\section{Affiliations}

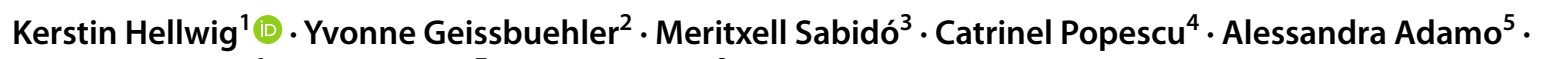
Joachim Klinger ${ }^{6}$. Asher Ornoy ${ }^{7}$ Peter Huppke ${ }^{8}$ on behalf of the European Interferon-beta Pregnancy Study Gro

up

1 Department of Neurology, St. Joseph and St. Elisabeth Hospital, Ruhr University, Gudrunstraße 56, 44791 Bochum, Germany

2 Global Medical Affairs, Novartis Pharma AG, Basel, Switzerland

3 Research and Development, Global Epidemiology, Merck KGaA, Darmstadt, Germany

4 Safety Surveillance and Aggregate Reports, Biogen Idec Ltd, Maidenhead, UK

5 Global Safety, Bayer AG, São Paulo, Brazil
7 Department of Medical Neurobiology, Hebrew University of Jerusalem, Jerusalem, Israel

8 Department of Pediatrics and Pediatric Neurology, University Medical Center, Göttingen, Germany 